\title{
The Pattern of Mortality in Dar es Salaam
}

\author{
By Obadia Nyongote (MD5-2006/2007)
}

\begin{abstract}
Objective: To assess mortality in Dar es Salaam by using data from the grave yards.
\end{abstract}

Design: Descriptive, cross-sectional grave yard based study.

Setting: Kinondoni grave yard (Kinondoni), Msimbazi grave yard (Ilala) and Chang'ombe grave yard (Temeke) in Dar es salaam, Tanzania.

Results: The study involved 1462 graves with 741 (50.7\%) being of males. Mortality in underfives (0-4) was $11.1 \%, 7.7 \%$ in $5-19$ years, $55.1 \%$ in 20-49 years while $12.5 \%$ comprised of above 65 years age group. Mortality trend was high among underfives then decreased at 5-19 age groups and again increased up to 30-34 years then decreased gradually. The age group 30-34 years made the peak value with $12.3 \%$ of all deaths. The study also showed that mortality is increasing with time as $1.7 \%$ of deaths occurred in 1980-1984 while 55.8\% occurred in 2000-2004.

Comparative analysis showed that there was concordant increase in numbers of reported AIDS cases as well as of mortality in Dar es Salaam from the year 1985 onwards. Before 1990's more males were dying compared to females but gradually the situation has reversed with time despite the constant general population ratio in Dar es Salaam.

Conclusion: Mortality was found to be high in underfives and people aged 20 to 49 years. The distribution pattern of deaths tally with the distribution pattern of deaths caused by Malaria and HIV/AIDS. Moreover both sex are similarly affected. That method of assessing mortality by studying graveyard data might be reliable to conclude that HIV/AIDS is a major cause of death.

Correspondence to: Dr. O. Nyongole Tel: $+255-713-535-907$

\section{INTRODUCTION}

Population living in the developing countries is characterized by a high burden of disease and mortality often involving children and young adults. During the past two decades countries in the sub-Saharan Africa, including Tanzania, have seen a rapid increase in child ${ }^{1}$ and adult mortality ${ }^{2}$, due to increase in poverty associated with poor health services ${ }^{1,2}$.Other factors include the resurgence and extended spread of malaria due to global warming and inadequate programs for mosquito control $^{7}$ and drug resistance to anti-malarial drugs ${ }^{8}$, the rapid spread of HIV/AIDS epidemic in urban and rural population since mid 1980's and a rise in non-communicable diseases due to change in lifestyle. Infant mortality rates have increased and so has death rates among adults.

Data from the ministry of health of Tanzania, indicated that about 18 million episodes of malaria are treated annually in health facilities countrywide. Furthermore it is estimated that 112500 people die from malaria in Tanzania mainland alone. These data have been used to conclude that malaria is the number one killer in the country, as it has repeatedly been reported in the media $3,5,10$.

On the other hand data from the community based studies done in Hai, Ilala and Morogoro districts indicated that HIV/AIDS is number one adult killer in those districts ${ }^{6}$. On the basis of this finding, it is reasonable therefore to assume that similar mortality pattern occur in other districts of Tanzania.

Data from AMMP and those from the ministry of health and the malaria control program are conflicting. Such inconsistency leaves the population and even scientists to wonder which of the two is valid. In addition confusing data may lead to policy uncertainty with regards to, messages to the society and resource allocation with dire consequences.

Malaria is associated with high case fatality among children aged less than five years and pregnant women. On the other hand, although HIV/AIDS affects people of all age groups, those in the age group 20-49 are 
particularly hard hit since the infection is predominantly spread through unprotected sexual intercourse ${ }^{9}$.

Performing autopsies on all deaths and reviewing causes of death as documented on death certificates are no doubt the best method of establishing the causes of death. However autopsies are socially not readily accepted in Tanzania and therefore are rarely done except for police cases. The AMMP used verbal autopsy to determine the cause of death. Fatal malaria commonly occurs among children under five years and to a lesser extent in pregnant women. In contrast, HIV disease including AIDS, mostly involves people in age group 20-49 years.

\section{METHODOLOGY}

\section{Study design}

Descriptive cross sectional grave yard based study.

\section{Study area}

The study was conducted at three major Grave Yards in Dar es Salaam, one from each municipality. Kinondoni grave yard in Kinondoni Municipality, Msimbazi grave yard in Ilala Municipality and Chang'ombe grave yard in Temeke Municipality.

\section{Target population}

The tombs/graves with deaths dated between 1980 and 2004

\section{Sample size}

Tombs which were labelled and the date of death seen during the period 1980 and 2004 were randomly selected and included in the study. The sample size was therefore $1462 ; 380$ tombs were randomly selected from Msimbazi grave yard,420 tombs from Chang,ombe grave yard and 662 tombs from kinondoni grave yard. The sample size for each grave yard was calculated as per population of the respective municipals.

\section{RESULTS}

\section{Table1.1: AGE AT THE TIME OF DEATH BY SEX}

\begin{tabular}{|c|c|c|c|c|c|c|}
\hline \multicolumn{7}{|c|}{ SEX } \\
\hline AGE GROUP & \multicolumn{2}{|c|}{ Males } & \multicolumn{2}{|c|}{ Females } & \multicolumn{2}{|c|}{ Total } \\
\hline $0-4$ & 90 & $(55 \%)$ & 73 & $(45 \%)$ & $\begin{array}{l}163 \\
(11.1 \%)\end{array}$ & \\
\hline $5-9$ & 24 & $(60 \%)$ & 16 & $(40 \%)$ & 40 & $(2.7 \%)$ \\
\hline $10-14$ & 17 & $(51 \%)$ & 16 & $(49 \%)$ & 33 & $(2.3 \%)$ \\
\hline $15-19$ & 18 & $(45 \%)$ & 22 & $(55 \%)$ & 40 & $(2.7 \%)$ \\
\hline $20-24$ & 37 & $(42 \%)$ & 51 & $(58 \%)$ & 88 & $(6.0 \%)$ \\
\hline $25-29$ & 56 & $(40 \%)$ & 82 & $(60 \%)$ & 138 & $(9.4 \%)$ \\
\hline $30-34$ & 68 & $(37 \%)$ & 112 & $(63 \%)$ & $\begin{array}{l}180 \\
(12.3 \%)\end{array}$ & \\
\hline $35-39$ & 81 & $(52 \%)$ & 72 & $(48 \%)$ & $\begin{array}{l}153 \\
(10.5 \%)\end{array}$ & \\
\hline $40-44$ & 85 & $(56 \%)$ & 66 & $(44 \%)$ & $\begin{array}{l}151 \\
(10.3 \%)\end{array}$ & \\
\hline $45-49$ & 54 & $(56 \%)$ & 42 & $(44 \%)$ & 96 & $(6.6 \%)$ \\
\hline $50-54$ & 36 & $(42 \%)$ & 48 & $(58 \%)$ & 84 & $(5.7 \%)$ \\
\hline $55-59$ & 36 & $(67 \%)$ & 17 & $(33 \%)$ & 53 & $(3.6 \%)$ \\
\hline $60-64$ & 37 & $(61 \%)$ & 23 & $(39 \%)$ & 60 & $(4.1 \%)$ \\
\hline $65++$ & 102 & $(55,7 \%)$ & 81 & $(44 \%)$ & $\begin{array}{l}183 \\
(12.5 \%)\end{array}$ & \\
\hline
\end{tabular}

Mortality was high among under fives (11.1\%) and the reproductive age group (20-49 years). The peak value (frequency) is at the age group 30-34 years.

About $12.5 \%$ died at the age above 65years. 
Table 1.2: DATE OF DEATH BY SEX

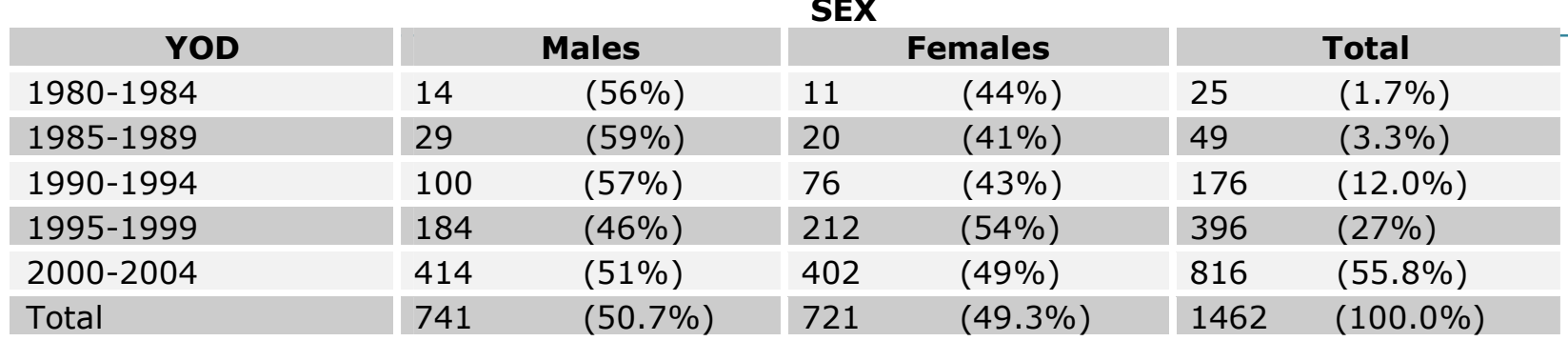

Mortality is increasing with time. In the years $1980-1984$ mortality percentage was $1.7 \%$ while in 2000-2004 it was 55.8\%. The table above may reflect that mortality has been increasing due to population growth in Dar es salaam.

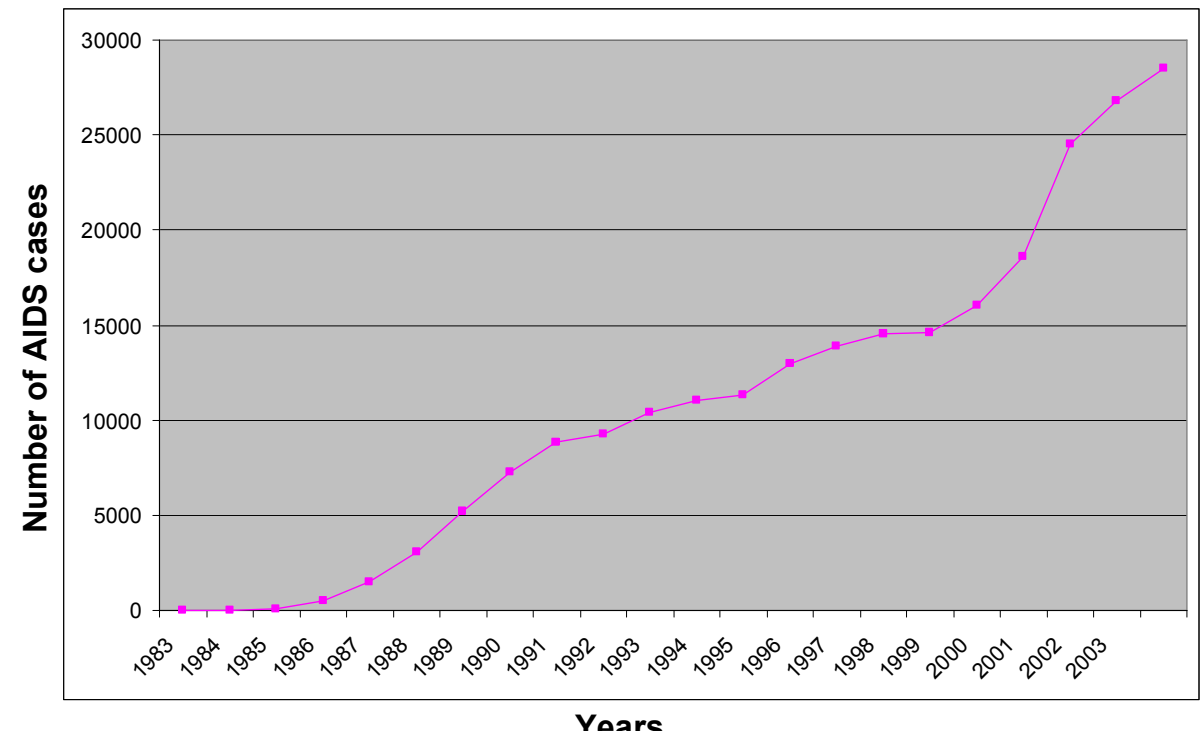

fig.1.3a: Trend of reported AIDS cases in Dar es Salaam from 1983 to 2004

\section{DISCUSSION}

The study revealed high mortality in under fives $(11.1 \%)$ and adults of reproductive age (20-49) with $55.1 \%$ but with no sex predilection just as previous $(50.7 \%$ for males and $49.3 \%$ for females) studies indicate.

Deaths that occurred at the age above 65 years comprised of $12.5 \%$ of nor study summate implying that life expectancy is low.

In contrary, studies have shown that underfives and pregnant women are the most affected groups with malaria ${ }^{10}$ but this study has revealed that the causes might be many but most probably HIV/AIDS since it involves mostly people of reproductive age.
Comparative analysis showed that there were increasing numbers of reported AIDS cases ${ }^{11}$ as well as mortality in Dar es Salaam from the year 1985 onwards. Before 1990 's more males were dying compared to females but gradually the situation has reversed with time despite the constant general population ratio in Dar es Salaam probably because of the combined effects of pregnancy and AIDS. Also increase in number of deaths may be due to Population increase in Dar es Salaam.

It was also revealed that with time mortality is increasing rapidly from 1985 making $55.8 \%$ of deaths (2000-2004) taking mortality as from 1980 . This is not very different from previous studies where they found that there was rapid spread of HIV/AIDS epidemic in urban and rural population since mid 1980's and a rise in 
non-communicable diseases due to change in lifestyle ${ }^{1,2,3}$.

\section{RECOMMENDATIONS}

The method of assessing mortality by grave yard data may be reliable as its analysis deals with solid data. AMMP findings were mainly from verbal autopsy, the method of this study reveals that the distribution pattern of deaths tally with the distribution pattern of deaths caused by Malaria and HIV/AID, both sex are affected equally therefore HIV/AIDS might be the major cause of deaths.

\section{CONCLUSION}

In this study, it was found that the underfive and people aged 20 to 49 years have high mortality which is increasing with time. Therefore the following are recommended:

1. Education on safer sex and PMTCT should be improved to prevent HIV transmission.

2. Prevention of Malaria and other diseases like fungal infections will delay AIDS development so reduction of mortality.

3. Education on behavioral change should be encouraged.

\section{ACKNOWLEDGEMENT}

I would like to express my sincere gratitude to all those who contributed to the production of this document like social \& Demographic statistics Manager, Said M.Aboud of National Bureau of statistics and Dar es Salaam Regional Medical Officer Dr.D. Mtasiwa for their guidance.

A lot of thanks to the Muhimbili University College of Health Sciences (MUCHS) administration for financial support to ensure the undertaking of the study.

Very special thanks to my supervisor, Professor K.Pallangyo, for offering me his time, teachings and whatever I needed from him in the development of this document I would also like to thank Professor S.Y. Maselle for his valuable final comments.

Lastly thanks to my fellow students who facilitated the data collection process.

\section{REFERENCES}

1. Walker N, Schwarthlandir B, Bryce J, Meeting international goals in child survival and HIV/AIDS. Lancet, 2002 360:284-289

2. Black RE, Moris SS, Bryce J, where and why are 10 million children dying every year? Lancet, 2003, 361:2226-2234

3. Bryce Jet all and the WHO child health Epidemiology reference group, WHO estimates of the causes of death in children. Lancet2005: 365:1147-1152

4. Africa Malaria Report 2003 www.rbm.who.int/amd2003/amr2003/ch1. htm-19k

5. Ministry of health Government of Tanzania; National Control Programmes Tanzania; National Malaria Medium term strategic plan 2003-2007.Government of Tanzania 2003, 1-66

6. Ministry of Health /Local council/AMMP www.ncl.ac.uk/ammp/site-file/Hai \% 202001.pdf

7. Africa malaria report 2003.http:mosquito. who.int/amd 2003/amr 2003/ summary.htm.

8. http/www. freerepublic.com/focus/fnews/902528/posts

9. www.tanzaniacare.org/htmls/AIDS Tanzania

10. The Guardian, (Tuesday September, 3,2005) Malaria, Tanzania biggest Killer disease (Control war is every body's business).

11. Tanzania National AIDS Control Programme, Report no.19, 2004; Pg 8 and 9.

12. Statistical Bureau, Population census reports 2002 . 